\title{
Florística e estrutura do estrato arbóreo de dois fragmentos de florestas decíduas às margens do rio Grande, em Alpinópolis e Passos, MG, Brasil ${ }^{1}$
}

\author{
Lívia Moreno Fagundes², Douglas Antônio de Carvalho ${ }^{3,5}$, Eduardo van den Berg ${ }^{3}$, \\ João José Granate Sá e Melo Marques ${ }^{4}$ e Evandro Luiz Mendonça Machado ${ }^{2}$
}

Recebido em 16/11/2005. Aceito em 3/08/2006

\begin{abstract}
RESUMO - (Florística e estrutura do estrato arbóreo de dois fragmentos de florestas decíduas às margens do rio Grande, em Alpinópolis e Passos, MG, Brasil). Realizou-se o levantamento da comunidade arbórea de dois fragmentos de florestas ripárias estacionais deciduais submontanas localizados na região do médio rio Grande e na margem esquerda deste rio, nos municípios de Alpinópolis e Passos, MG


fitossociologia das florestas que margeiam os cursos d'água em Minas Gerais e de avaliar as correlações entre variações estruturais e variáveis ambientais. Foram analisados aspectos da estrutura (densidade e área basal), composição, distribuição e diversidade de espécies. Foram alocadas 25 parcelas de $20 \times 20 \mathrm{~m}$ para amostragem dos indivíduos arbóreos com diâmetro à altura do peito $(\mathrm{DAP}) \geq 5 \mathrm{~cm}$, onde também foram coletados dados topográficos e amostras de solo superficial para análises químicas e texturais. Foram registrados 811 indivíduos, 65 espécies, 55 gêneros e 28 famílias, bem como três subgrupos de solos e duas classes de drenagem. Anadenanthera colubrina e Myracrodruon urundeuva foram marcantemente as espécies mais importantes. Uma análise de correspondência canônica (CCA) detectou um gradiente curto, com poucas substituições de espécies e predominância da variação nas abundâncias das espécies arbóreas, ligado principalmente à drenagem e ao desnível.
\end{abstract}

Palavras-chave: Floresta decídua, estrato arbóreo, diversidade de espécies, variáveis ambientais

\begin{abstract}
Floristics and structure of the tree layer of two deciduous forest fragments on the Rio Grande, in Alpinópolis and Passos, Minas Gerais State, Brazil). The tree layer was surveyed in two fragments of submontane deciduous riparian forest on the left bank of the mid-course Rio Grande, in Alpinópolis and Passos municipalities, MG (2041'S; 46⒉' 'W; 2040'S; 46 $27^{\circ}$ 'W; altitude 680 to $750 \mathrm{~m}$ ). The aim was to study the flora and phytosociology of riparian forests in Minas Gerais and to assess the correlation between forest structure variation and environmental variables. Structure (density and basal area), species composition, distribution and diversity were analyzed. All trees with $\mathrm{dbh} \geq 5 \mathrm{~cm}$ were sampled in 25 plots $(20 \times 20 \mathrm{~m})$; topographic data and soil samples for chemical and textural analyses were collected in these plots. A total of 811 trees, 65 species, 55 genera and 28 families were recorded, as well as three soil groups and two drainage classes. Anadenanthera colubrina and Myracrodruon urundeuva were clearly the most important species. Canonical correspondence analysis detected a short gradient with low species substitution and species abundances varying mainly in relation to drainage and slope variables.
\end{abstract}

Key words: Deciduous forest, tree layer, species diversity, environmental variables

\section{Introdução}

As florestas ripárias são formações que se encontram associadas aos corpos d'água, ao longo dos quais podem estender-se por centenas de metros a partir das margens. Tais formações apresentam marcantes variações na composição florística e na estrutura comunitária, dependendo das interações que se estabelecem entre o ecossistema aquático e o ambiente terrestre adjacente (Brinson 1990). Os ecossistemas ripários, de maneira geral, sofrem constantes perturbações naturais e/ou antrópicas e convivem com a dinâmica erosiva e de sedimentação dos cursos d'água, absorvendo, assim, os impactos que ocorrem na bacia hidrográfica (van den Berg \& Oliveira Filho 2000) e, por possuírem solos férteis, são, com freqüência, utilizados para atividades agropecuárias. As florestas ripárias da região Centro-Sul do Brasil se

\footnotetext{
1 Parte da dissertação de Mestrado da primeira Autora

2 Universidade Federal de Lavras, Departamento de Engenharia Florestal, 37200-000 Lavras, MG, Brasil

3 Universidade Federal de Lavras, Departamento de Biologia

4 Universidade Federal de Lavras, Departamento de Ciências do Solo

5 Autor para correspondência: douglasc@ufla.br
} 
encontram em situação crítica, fato que impulsionou, nos últimos anos, uma série de iniciativas visando conservar ou recuperar essas florestas (Barbosa 1989).

Vários estudos têm mostrado que um dos principais fatores que atuam na composição florística e estrutura das florestas é a heterogeneidade ambiental, cujos efeitos podem ser observados mesmo no interior de pequenos fragmentos (Rodrigues \& Nave 2000; Oliveira Filho et al. 1994a; 1998; Durigan et al. 2000; Botrel et al. 2002). Essa heterogeneidade é resultado da diversidade de fatores que interagem nas comunidades e a resposta das espécies a esses fatores faz com que cada local tenha algumas características próprias, possibilitando observar tendências que podem responder algumas perguntas e gerar várias outras, funcionando como força motriz para novos estudos.

Os estudos dos aspectos florísticos e ecológicos das florestas ripárias brasileiras tiveram início na Bacia Amazônica (Black et al. 1950; Pires \& Koury 1958; Rodrigues 1961) estendendo-se depois a outras regiões do país devido principalmente, à necessidade e à urgência de preservação, ou enriquecimento e/ou recuperação dos relictos florestais remanescentes.

No Estado de Minas Gerais, estudos envolvendo análises florísticas, estruturais e ecológicas da vegetação de formações florestais ciliares foram desenvolvidos nas bacias dos rios Grande (Gavilanes et al. 1992; Carvalho et al. 1995a; 1995b; 1996; 2005a; Oliveira Filho et al. 1994a; 1994b; 1994c; 1994d; 1997; Vilela et al. 1993; 1994; 1995; 1999), Paranaíba (Carvalho et al. 1999; Oliveira Filho et al. 1998), Doce (Carvalho et al. 2000b; Oliveira Filho et al. 2004) e São Francisco (Carvalho et al. 2000a; 2005b; Oliveira Filho et al. 2001).

O presente trabalho tem por objetivo contribuir para o conhecimento da florística e fitossociologia das florestas que margeiam os cursos d'água de Minas Gerais através do levantamento da comunidade arbórea de dois fragmentos de florestas ripárias, deciduais, próximos um do outro e adjacentes ao curso do rio Grande, nos municípios de Alpinópolis e Passos, MG, verificando também, possíveis correlações entre as variações em suas estruturas e variáveis ambientais.

\section{Material e métodos}

O Estado de Minas Gerais possui 17 bacias hidrográficas (IGAM 1998), dentre as quais está a bacia hidrográfica do rio Grande. Esta, em função de sua composição hidrológica, pode ser subdividida em Alto, Médio e Baixo Rio Grande. O presente trabalho foi realizado na região do Médio Rio Grande, em dois fragmentos ripários de florestas estacionais deciduais submontanas (Veloso et al. 1991), localizados na margem esquerda do rio. O primeiro fragmento, a cerca de $5 \mathrm{~km}$ a jusante da Hidrelétrica de Furnas, apresenta área de aproximadamente 5 hectares, é delimitado por pastagem, e localiza-se no município de Alpinópolis $\left(20^{\circ} 41^{\prime} \mathrm{S} ; 46^{\circ} 22^{\prime} \mathrm{W}\right.$; altitude variando entre $680 \mathrm{a}$ $700 \mathrm{~m}$ ). O segundo, com área total de aproximadamente 20 hectares, além da porção recoberta por floresta relativamente bem conservada, engloba também áreas de floresta secundária inicial (capoeira) e possui delimitação com plantação de cana, está localizado no município de Passos (2040'S; 46⒉' W; altitude variando entre 680 a $750 \mathrm{~m}$ ) e dista, do primeiro, aproximadamente $5 \mathrm{~km}$, rio abaixo. A região apresenta um clima $\mathrm{Cwb}$, segundo Köppen, ou seja, clima mesotérmico com verões brandos e suaves e estiagens de inverno, possuindo média do mês mais frio abaixo de $18^{\circ} \mathrm{C}$ (BRASIL 1992). O regime de chuvas tropicais estende-se de maneira generalizada por toda área, notando-se uma estação seca bem definida. O período seco máximo é verificado nos meses de junho, julho e agosto, com médias mensais abaixo de $30 \mathrm{~mm}$. Durante o período chuvoso, os meses que acusam maiores precipitações são dezembro e janeiro, com médias mensais variando de 190 a $270 \mathrm{~mm}$. A média pluviométrica anual é de $1.200 \mathrm{~mm}$ (BRASIL 1992). A região está localizada na zona fisiográfica dos Planaltos da Canastra, junto à depressão do rio Grande, Bacia do Rio Paraná (RADAMBRASIL 1983), ocupada por rochas do Proterozóico Superior (1100-570 Ma) pertencentes ao Grupo Araxá (micaxistos, quartzitos, anfibólitos, gnaisses e formações ferríferas) (Soares et al. 1994).

A comunidade arbórea foi amostrada em 25 parcelas de $20 \times 20 \mathrm{~m}$, totalizando 1,00 ha de área amostrada. No primeiro fragmento (Alpinópolis) foram alocadas 12 parcelas, arranjadas em três transectos no alinhamento $30^{\circ} \mathrm{NO}$ (Fig. 1A), distando 30 metros um do outro e com $20 \mathrm{~m}$ entre parcelas. No segundo fragmento (Passos), as 13 parcelas foram arranjadas, no alinhamento Leste-Oeste, em seis transectos, distantes $20 \mathrm{~m}$ um do outro com $20 \mathrm{~m}$ entre parcelas (Fig. 1B). Um levantamento topográfico foi realizado nas áreas, com auxílio de GPS, trena, bússola e hipsômetro de Blume-Leiss. Com os dados deste levantamento, foi produzida uma representação tridimensional das áreas (Fig. 1A, 1B) e foram extraídas três variáveis topográficas por parcela: (a) cota média, obtida da média das quatro cotas dos vértices (b) 
A

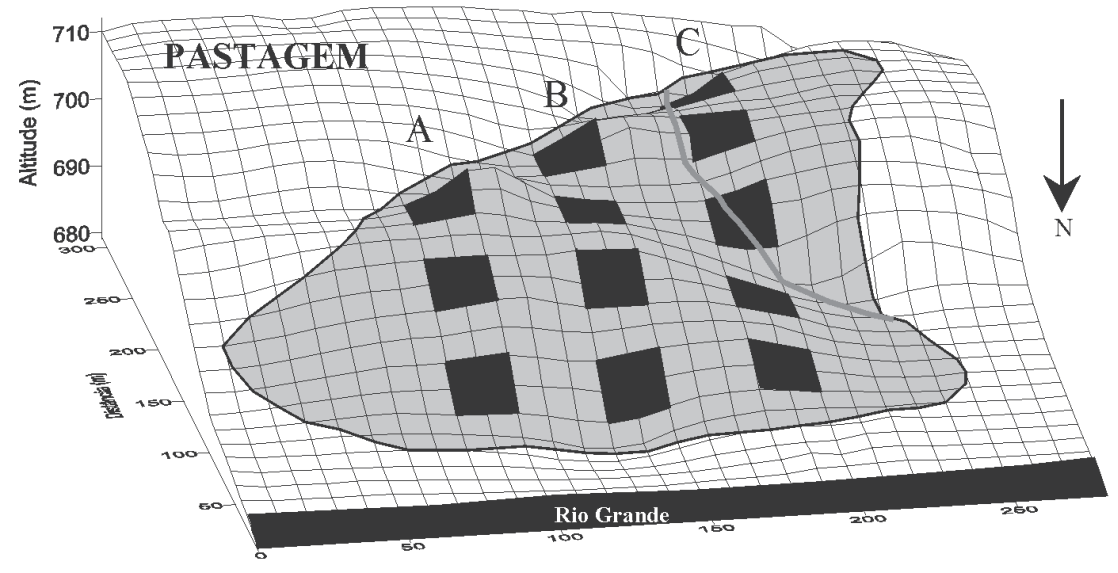

B
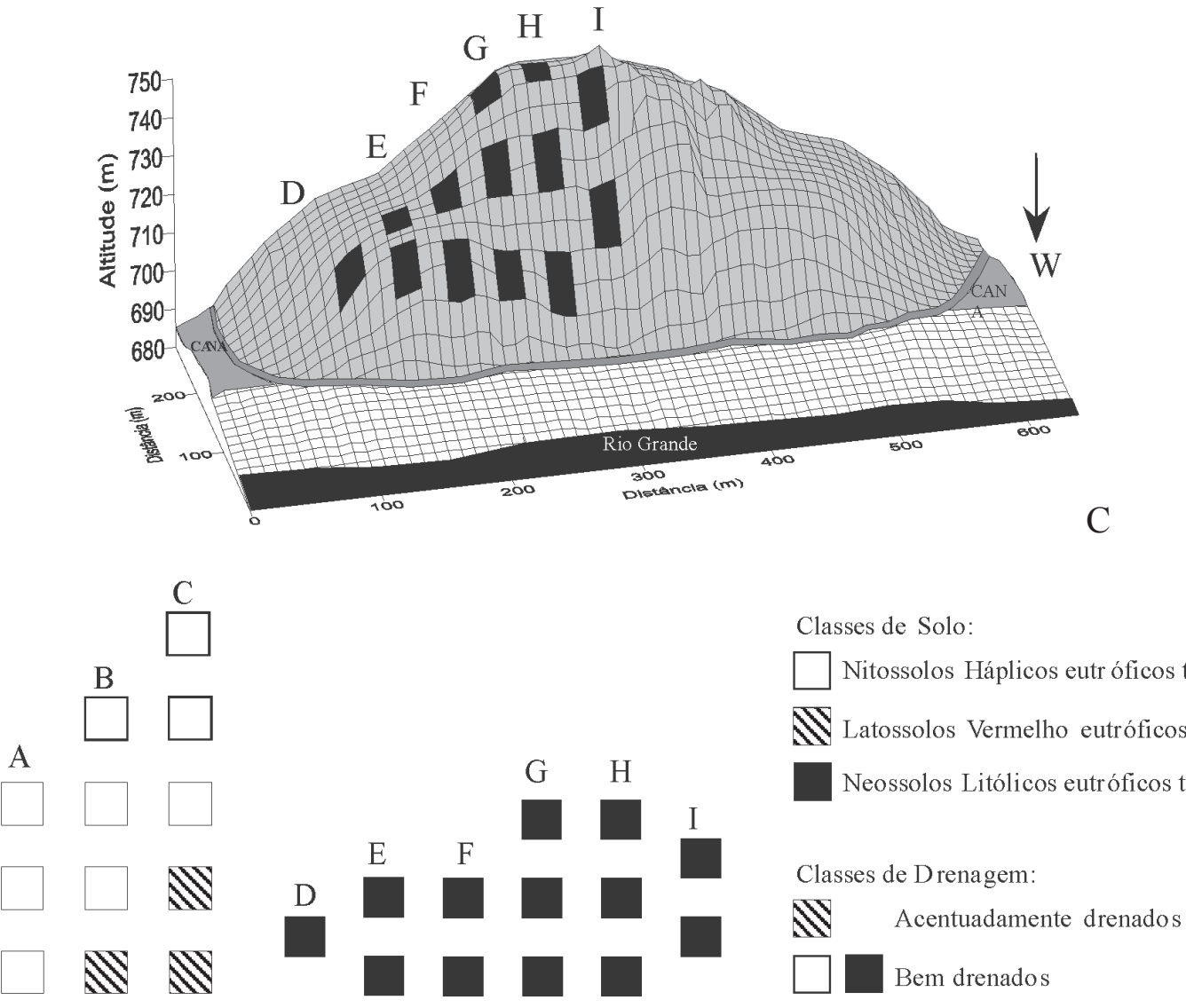

Figura 1. Grade de superfície, com espaçamento entre linhas de 10 m, mostrando a área do fragmento de Alpinópolis, MG, (A) e do fragmento de Passos, MG (B) e a distribuição das 25 parcelas de 20×20 m utilizadas para amostrar a comunidade arbórea e distribuição das parcelas amostrais segundo as classes de solos e de drenagem (C). 
desnível, obtido da diferença entre as cotas máxima e mínima e (c) declividade média, obtida da média da declividade dos quatro lados das parcelas. Em cada parcela foram registrados todos os indivíduos arbóreos vivos e com circunferência à altura de $1,30 \mathrm{~m}$ (CAP) igual ou superior a $15,7 \mathrm{~cm}$, o que equivale a um diâmetro (DAP) de 5,0 cm. Os indivíduos com caules divididos desde a base foram incluídos no levantamento quando a área basal total dos caules correspondia a $\mathrm{CAP} \geq 15,7 \mathrm{~cm}$. Cada indivíduo foi marcado com etiqueta de alumínio numerada, sendo registrados seu número, a espécie, o valor das CAPs, medido com fita métrica, e altura total, estimada com auxílio de vara graduada. Foram coletadas amostras de material botânico dos espécimes registrados nas parcelas para posterior identificação. A herborização do material botânico foi feita no Herbário ESAL do Departamento de Biologia da Universidade Federal de Lavras (UFLA) e a coleção testemunha foi incorporada ao acervo do mesmo. A identificação do material botânico foi realizada com a utilização de coleções botânicas já existentes no Herbário ESAL e também por meio de consultas à literatura, à especialistas e à coleção do Herbário UEC da Universidade Estadual de Campinas (UNICAMP). As espécies foram classificadas nas famílias reconhecidas pelo sistema do Angiosperm Phylogeny Group II (APG II 2003). A estrutura da comunidade arbórea foi descrita a partir do cálculo dos parâmetros fitossociológicos descritos por MuellerDombois \& Ellenberg (1974) para as espécies, com adição da altura máxima para oferecer uma descrição do tamanho máximo alcançado por elas. Os cálculos foram efetuados pelo programa FITOPAC 2 (Shepherd 1994). A diversidade de espécies foi avaliada por meio dos índices de diversidade de Shannon $\left(H^{\prime}\right)$ e de equabilidade de Pielou $\left(J^{\prime}\right)$ em base logarítmica natural (Brower \& Zar 1984).

Os solos predominantes em cada parcela foram classificados no campo de acordo com o Sistema Brasileiro de Classificação de Solos (EMBRAPA 1999), chegando até o nível de subgrupo (ou $4^{\circ}$ nível categórico) e incluindo as classes de drenagem. No centro de cada parcela, foram coletadas amostras simples do solo superficial (0-20 $\mathrm{cm}$ de profundidade) de cerca de $500 \mathrm{ml}$. As análises químicas e texturais das amostras foram realizadas no Laboratório de Análise de Solos da UFLA seguindo o protocolo da EMBRAPA (1997). As variáveis de solo medidas foram: $\mathrm{pH}$; teores de $\mathrm{P}, \mathrm{K}, \mathrm{Ca}, \mathrm{Mg}, \mathrm{Al}, \mathrm{H}+\mathrm{Al}$; soma de bases (valor $\mathrm{S}$ ), saturação por bases (valor $\mathrm{V}$ ); matéria orgânica e teores de areia, silte e argila.
Para analisar as correlações entre os gradientes ambientais e vegetacionais foi empregada uma análise de correspondência canônica (CCA) (ter Braak 1987) utilizando o programa PC-ORD for Windows versão 4.14 (McCune \& Mefford 1999). De acordo com as recomendações de ter Braak (1995), os valores de abundância foram transformados pela expressão $\log _{10}$ $(a+1)$ para compensar os desvios causados por alguns poucos valores muito elevados. A matriz de abundância das espécies foi constituída do número de indivíduos por parcela das espécies que apresentavam dois ou mais indivíduos na amostra total, sendo assim excluídas das análises as espécies raras sensu Martins (1989), ou seja, aquelas que foram amostradas por um único indivíduo. A matriz de variáveis ambientais por parcela incluiu, a princípio, as três variáveis topográficas, a classe de drenagem dos solos, além de todas as 15 variáveis químicas e texturais dos solos, totalizando 19 variáveis contínuas. As classes de drenagem dos solos foram expressas como variável ordinal ('ranking'), atribuída às categorias pela EMBRAPA (1999): 5 - bem drenado e 6 - acentuadamente drenado (outras classes de drenagem não foram representadas). Após realizar uma CCA preliminar, foram eliminadas 16 variáveis ambientais fracamente correlacionadas ou altamente redundantes com outras variáveis. A CCA final foi processada com as três variáveis mais representativas e mais fortemente correlacionadas com os eixos de ordenação nos dois fragmentos: drenagem, soma de bases e desnível.

\section{Resultados}

Variáveis topográficas e edáficas - O relevo é movimentado em Alpinópolis e forte ondulado em Passos. Em Alpinópolis foram identificados Nitossolo Háplico eutrófico típico A moderado argiloso e Latossolo Vermelho eutrófico típico; o primeiro nas parcelas localizadas em áreas mais elevadas e o segundo na direção das parcelas localizadas em áreas mais próximas ao rio, onde há um aumento na profundidade do solo (Fig. 1C). Em Passos, observou-se a presença de Neossolo Litólico eutrófico típico A chernozêmico textura média. $\mathrm{O}$ valor das variáveis topográficas e variáveis químicas e texturais dos solos são apresentados na Tab. 1. As diferenças foram entre os Neossolos e os demais solos. O desnível explica-se pela elevada declividade do fragmento de Passos. A menor concentração de $\mathrm{P}$ foi encontrada no Latossolo, o qual é muito intemperizado, o que favorece uma forte adsorção desse elemento em óxidos de ferro, 
Tabela 1. Variáveis topográficas, químicas e texturais dos solos de 25 amostras do solo superficial (0-20 cm de profundidade) coletadas em parcelas nas florestas ripárias às margens do rio Grande, em Alpinópolis e Passos, MG. Os valores são médias \pm desvio padrão do número de amostras $(\mathrm{N})$ das três classes de solos. $\mathrm{H}^{+}+\mathrm{Al}^{+++}$(acidez potencial a $\mathrm{pH}$ 7); $\mathrm{T}$ (Capacidade de troca de cátions-CTC a pH 7); $\mathrm{t}$ (CTC efetiva).

\begin{tabular}{|c|c|c|c|}
\hline Variáveis & $\begin{array}{l}\text { Nitossolos } \\
\quad(\mathrm{N}=9)\end{array}$ & $\begin{array}{l}\text { Latossolos } \\
\qquad(\mathrm{N}=3)\end{array}$ & $\begin{array}{c}\text { Neossolos } \\
(\mathrm{N}=13)\end{array}$ \\
\hline Cota média (m) & $691,7 \pm 6,5$ & $702,2 \pm 0,7$ & $711,9 \pm 18,1$ \\
\hline Desnível (m) & $5,5 \pm 2,1$ & $4,8 \pm 0,6$ & $13,9 \pm 3,4$ \\
\hline Declividade média (graus) & $15,3 \pm 2,3$ & $13,1 \pm 2,1$ & $35,2 \pm 5,4$ \\
\hline pH em água & $6,0 \pm 0,2$ & $6,0 \pm 0,4$ & $6,0 \pm 0,3$ \\
\hline $\mathrm{P}-\operatorname{Mehlich}\left(\mathrm{mg} \mathrm{dm}^{-3}\right)$ & $1,5 \pm 0,4$ & $1,2 \pm 0,3$ & $4,2 \pm 3,0$ \\
\hline $\left.\mathrm{K}^{+}(\mathrm{mg} \mathrm{dm})^{3}\right)$ & $179,4 \pm 32,9$ & $174,7 \pm 31,2$ & $144,1 \pm 25,5$ \\
\hline $\mathrm{Ca}^{++}\left(\mathrm{cmolc} \mathrm{dm}^{-3}\right)$ & $7,8 \pm 1,7$ & $6,8 \pm 0,4$ & $7,6 \pm 1,9$ \\
\hline $\mathrm{Mg}^{++}\left(\mathrm{cmolc} \mathrm{dm}^{-3}\right)$ & $2,5 \pm 0,6$ & $2,5 \pm 0,4$ & $2,8 \pm 0,5$ \\
\hline $\mathrm{Al}^{+++}\left(\mathrm{cmolc} \mathrm{dm}^{-3}\right)$ & $0,1 \pm 0,1$ & $0,0 \pm 0,0$ & $0,0 \pm 0,0$ \\
\hline m - saturação por alumínio (\%) & $0,3 \pm 0,5$ & $0,0 \pm 0,0$ & $0,2 \pm 0,4$ \\
\hline $\mathrm{H}^{+}+\mathrm{Al}^{+++}\left(\mathrm{cmolc} \mathrm{dm}^{-3}\right)$ & $3,3 \pm 0,5$ & $3,3 \pm 0,3$ & $3,6 \pm 0,6$ \\
\hline $\mathrm{T}\left(\mathrm{cmolc} \mathrm{dm}^{-3}\right)$ & $14,2 \pm 2,3$ & $13,0 \pm 1,1$ & $14,4 \pm 2,3$ \\
\hline $\mathrm{t}\left(\mathrm{cmolc} \mathrm{dm}^{-3}\right)$ & $10,9 \pm 1,8$ & $9,7 \pm 0,8$ & $10,8 \pm 1,7$ \\
\hline $\mathrm{S}-$ soma de bases $\left(\mathrm{cmolc} \mathrm{dm}^{-3}\right)$ & $10,8 \pm 1,7$ & $9,7 \pm 0,8$ & $10,8 \pm 1,7$ \\
\hline V - saturação para bases (\%) & $75,9 \pm 8,5$ & $74,6 \pm 7,6$ & $75,2 \pm 7,6$ \\
\hline Matéria orgânica $\left(\right.$ dag $\left.\mathrm{kg}^{-1}\right)$ & $4,1 \pm 0,6$ & $3,8 \pm 0,2$ & $4,6 \pm 0,6$ \\
\hline Areia $(\%)$ & $28,0 \pm 5,3$ & $32,7 \pm 9,6$ & $48,8 \pm 3,8$ \\
\hline Silte $(\%)$ & $33,5 \pm 1,9$ & $32,0 \pm 1,7$ & $17,5 \pm 7,9$ \\
\hline Argila (\%) & $38,4 \pm 5,4$ & $35,3 \pm 8,0$ & $33,6 \pm 8,4$ \\
\hline
\end{tabular}

permanecendo, assim, pouco disponível. Sendo derivado de rochas ricas em $\mathrm{P}$, o Nitossolo apresenta teores desse elemento superiores aos do Latossolo, porém não tão altos como nos Neossolos, já que estes são solos muito pouco alterados pelo intemperismo. A presença de feldspatos no material de origem do Nitossolo e Latossolo, presentes no fragmento de Alpinópolis fizeram com que teores de $\mathrm{K}$ fossem ali mais elevados. Teores mais elevados de matéria orgânica nos Neossolos se justificam pela presença ali de um sub-bosque denso, e espessa camada de serrapilheira. Solos jovens, como os Neossolos, tendem a possuir partículas mais grosseiras, já que não houve intemperização suficiente para formar quantidades significativas de argila. Latossolos e Nitossolos, por outro lado, são solos razoavelmente imtemperizados, havendo portanto uma maior quantidade de partículas finas neles. Comparando-se o Nitossolo e o Latossolo constata-se que o primeiro é ligeiramente mais argiloso. A razão disso pode estar ligada ao material de origem do Nitossolo, rochas máficas, as quais possuem pouco ou nenhum conteúdo de quartzo, originando, normalmente, solos mais argilosos.

Florística, estrutura e diversidade da comunidade arbórea - Foram identificadas 65 espécies (50 no fragmento de Alpinópolis e 39 no fragmento de Passos), pertencentes a 55 gêneros e 28 famílias (24 no fragmento de Alpinópolis e 21 no fragmento de Passos), sendo que 24 espécies e 17 famílias foram comuns ao dois fragmentos (Tab. 2). Destacaram-se as famílias Fabaceae, com 16 espécies, Rubiaceae, com seis, Bignoniaceae, com cinco e Anacardiaceae, Apocynaceae, Malvaceae, Meliaceae e Myrtaceae com três cada, que juntas compreendem $64,6 \%$ das espécies. As famílias representadas por somente uma espécie somaram 17 (26,1\% das espécies). Os gêneros com maior número de espécies foram Tabebuia (4), Trichilia e Aspidosperma (3), Campomanesia, Guettarda e Machaerium (2), que juntos, contribuíram com $24,6 \%$ das espécies. Nas parcelas foram amostrados 811 indivíduos (525 no fragmento de Alpinópolis e 286 no de Passos) pertencentes a 61 espécies, sendo que quatro espécies $(6,1 \%)$ foram registradas fora das parcelas. Quatro famílias contribuíram com $81,8 \%$ do número total de indivíduos, com Fabaceae ocupando a primeira posição $(36,9 \%)$, seguida de Anacardiaceae (20,5\%), Meliaceae (16,4\%) e Sapindaceae (8\%). As dez espécies com maior densidade totalizaram $74,8 \%$ do número total de indivíduos, destacando-se Myracrodruon urundeuva (20,3\%), Anadenanthera colubrina (15,8\%), Trichilia 
Tabela 2. Espécies arbóreas registradas nas florestas ripárias de Alpinópolis, MG (A) e Passos, MG (B), dispostas em ordem alfabética de famílias botânicas e acompanhadas de seus respectivos números de registro $(\mathrm{Rg})$ no Herbário ESAL e parâmetros quantitativos obtidos na amostra de 25 parcelas de $20 \times 20 \mathrm{~m}$ : h = altura máxima; $\mathrm{N}=$ número de indivíduos; $\mathrm{PC}=$ número de parcelas com ocorrência da espécie; $\mathrm{AB}$ = área basal; e VI = valor de importância. Espécies com N = 'Flora' foram registradas apenas fora das parcelas amostrais.

\begin{tabular}{|c|c|c|c|c|c|c|c|c|c|c|}
\hline \multirow[t]{2}{*}{ Famílias/Espécies } & \multirow[t]{2}{*}{$\mathrm{Rg}$} & \multirow{2}{*}{$\begin{array}{c}\mathrm{h} \\
(\mathrm{m})\end{array}$} & \multicolumn{2}{|c|}{$\mathrm{N}$} & \multicolumn{2}{|c|}{$\mathrm{PC}$} & \multicolumn{2}{|c|}{$\mathrm{AB} \quad\left(\mathrm{m}^{2}\right)$} & \multicolumn{2}{|c|}{ VI } \\
\hline & & & A & $\mathrm{P}$ & A & $\mathrm{P}$ & A & $\mathrm{P}$ & A & $\mathrm{P}$ \\
\hline \multicolumn{11}{|l|}{ ANACARDIACEAE } \\
\hline Astronium fraxinifolium Schott & 18067 & 20,0 & 0 & 1 & 0 & 1 & 0 & 0,0563 & 0 & 1,64 \\
\hline Myracrodruon urundeuva Allem. & 14607 & 23,0 & 126 & 39 & 12 & 11 & 9,6149 & 2,2791 & 85,74 & 42,66 \\
\hline Tapirira guianensis Aublet & 3718 & 11,0 & 1 & 0 & 1 & 0 & 0,0283 & 0 & 1,06 & 0 \\
\hline \multicolumn{11}{|l|}{ ANNONACEAE } \\
\hline $\begin{array}{l}\text { Rollinia sylvatica (A.St.-Hil.)Mart. } \\
\text { APOCYNACEAE }\end{array}$ & 18068 & 17,0 & 1 & 3 & 1 & 2 & 0,0127 & 0,0409 & 0,97 & 2,22 \\
\hline Aspidosperma discolor A.DC. & 18069 & 18,0 & 0 & 14 & 0 & 8 & 0 & 0,6715 & 0 & 16,41 \\
\hline A. parvifolium A.DC. & 18070 & 17,0 & 2 & 0 & 2 & 0 & 0,0725 & 0 & 2,20 & 0 \\
\hline A. subincanum Mart. & 18071 & 15,0 & 0 & 8 & 0 & 4 & 0 & 0,1363 & 0 & 5,25 \\
\hline \multicolumn{11}{|l|}{ ARALIACEAE } \\
\hline $\begin{array}{l}\text { Aralia warmingiana (E. Marchal) Harms } \\
\text { ARECACEAE }\end{array}$ & 18072 & 12,0 & 4 & 6 & 2 & 5 & 0,0236 & 0,1005 & 2,31 & 5,52 \\
\hline $\begin{array}{l}\text { Syagrus oleracea (Mart.) Becc. } \\
\text { BIGNONIACEAE }\end{array}$ & 18073 & 2,5 & 0 & 1 & 0 & 1 & 0 & 0,0028 & 0 & 0,85 \\
\hline Jacaranda cuspidifolia Mart. ex A.DC. & 18074 & 13,0 & 1 & 0 & 1 & 0 & 0,0335 & 0 & 1,09 & 0 \\
\hline Tabebuia heptaphylla (Vell.) Toledo & 15147 & 4,5 & 0 & 1 & 0 & 1 & 0 & 0,0027 & 0 & 0,85 \\
\hline T. impetiginosa (Mart. ex DC.) & 18075 & & Flora & & & & & & & \\
\hline T. roseo-alba (Ridley) Sandw. Standl. & 18076 & 13,0 & 3 & 2 & 2 & 2 & 0,0212 & 0,0490 & 2,11 & 2,34 \\
\hline T. serratifolia (Vahl) Nichols & 18077 & 7,0 & 1 & 3 & 1 & 3 & 0,0028 & 0,0101 & 0,91 & 2,57 \\
\hline \multicolumn{11}{|l|}{ CANNABACEAE } \\
\hline Celtis spinosa Sprengel & 14683 & 8,0 & 3 & 2 & 2 & 2 & 0,0137 & 0,0100 & 2,07 & 1,76 \\
\hline \multicolumn{11}{|l|}{ CARICACEAE } \\
\hline $\begin{array}{l}\text { Jacaratia spinosa (Aubl.) A.DC. } \\
\text { CELASTRACEAE }\end{array}$ & 18078 & & Flora & & & & & & & \\
\hline Maytenus robusta Reiseek & 18079 & 16,0 & 4 & 7 & 3 & 5 & 0,0344 & 0,0851 & 3,08 & 5,29 \\
\hline \multicolumn{11}{|l|}{ CLETHRACEAE } \\
\hline $\begin{array}{l}\text { Clethra scabra Pers. } \\
\text { COMBRETACEAE }\end{array}$ & 18080 & 13,0 & 1 & 0 & 1 & 0 & 0,0749 & 0 & 1,31 & 0 \\
\hline $\begin{array}{l}\text { Terminalia glabrescens Mart. } \\
\text { EUPHORBIACEAE }\end{array}$ & 18081 & 14,0 & 1 & 1 & 1 & 1 & 0,0181 & 0,0030 & 1,00 & 0,85 \\
\hline Pera glabrata (Schott) Poepp. & 2992 & 9,0 & 2 & 0 & 1 & 0 & 0,0044 & 0 & 1,11 & 0 \\
\hline \multicolumn{11}{|l|}{ FABACEAE - CAES. } \\
\hline Bauhinia longifolia (Bongard) Steudel & 18082 & 8,0 & 1 & 5 & 1 & 2 & 0,0030 & 0,0256 & 0,92 & 1,99 \\
\hline Copaifera langsdorfii Desf. & 3564 & 14,0 & 7 & 1 & 2 & 1 & 0,0247 & 0,0097 & 2,89 & 0,95 \\
\hline Peltophorum dubium (Sprengel) Taub. & 18083 & 10,0 & 3 & 2 & 3 & 1 & 0,0160 & 0,0193 & 2,79 & 1,09 \\
\hline \multicolumn{11}{|l|}{ FABACEAE - FAB. } \\
\hline Holocalyx balansae Micheli & 18084 & 18,0 & 23 & 33 & 8 & 10 & 0,1346 & 0,6730 & 10,80 & 18,04 \\
\hline $\begin{array}{l}\text { Lonchocarpus cultratus (Vell.) A.Tozzi } \\
\text { \& H.C.Lima }\end{array}$ & 18085 & 18,0 & 8 & 0 & 5 & 0 & 0,0975 & 0 & 5,61 & 0 \\
\hline Machaerium brasiliense Vogel & 18086 & 17,0 & 17 & 3 & 9 & 3 & 0,2112 & 0,0200 & 10,79 & 2,72 \\
\hline M. hirtum (Vell.) Stelfeld & 18087 & 10,0 & 5 & 0 & 2 & 0 & 0,0727 & 0 & 2,77 & 0 \\
\hline Myroxylon peruiferum L.f. & 18088 & 11,0 & 2 & 1 & 2 & 1 & 0,0105 & 0,0087 & 1,86 & 0,93 \\
\hline Platycyamus regnellii Benth. & 1935 & 7,0 & 0 & 1 & 0 & 1 & 0 & 0,0039 & 0 & 0,86 \\
\hline Sweetia fruticosa Sprengel & 18089 & 16,0 & 7 & 14 & 5 & 8 & 0,0266 & 0,2144 & 5,03 & 9,63 \\
\hline \multicolumn{11}{|l|}{ FABACEAE - MIM. } \\
\hline Acacia glomerosa Benth. & 18090 & 4,0 & 1 & 0 & 1 & 0 & 0,0030 & 0 & 0,92 & 0 \\
\hline $\begin{array}{l}\text { Albizia niopoides (Spruce ex Benth.) } \\
\text { Burkart. }\end{array}$ & 18091 & 4,5 & 1 & & 1 & & 0,0058 & & 0,93 & \\
\hline Anadenanthera colubrina (Vell.) Brenan & 18092 & 26,0 & 65 & 63 & 12 & 13 & 5,5770 & 7,9471 & 51,77 & 128,29 \\
\hline $\begin{array}{l}\text { Chloroleucon tortum (Mart.) Pittier } \\
\text { ex Barneby \& Grimes }\end{array}$ & 18093 & 18,0 & 0 & 3 & 0 & 2 & 0 & 0,0243 & 0 & 1,97 \\
\hline Inga striata Benth. & 18094 & 15,0 & 5 & 0 & 3 & 0 & 0,0689 & 0 & 3,46 & 0 \\
\hline Piptadenia gonoacantha (Mart.) Macbr. & 12865 & 16,0 & 18 & 10 & 3 & 7 & 0,2552 & 0,0568 & 6,97 & $\begin{array}{c}6,49 \\
\text { continuc }\end{array}$ \\
\hline
\end{tabular}


Tabela 2 (continuação)

\begin{tabular}{|c|c|c|c|c|c|c|c|c|c|c|}
\hline \multirow[t]{2}{*}{ Famílias/Espécies } & \multirow[t]{2}{*}{$\operatorname{Rg}$} & \multirow{2}{*}{$\begin{array}{c}\mathrm{h} \\
(\mathrm{m})\end{array}$} & \multicolumn{2}{|c|}{$\mathrm{N}$} & \multicolumn{2}{|c|}{$\mathrm{PC}$} & \multicolumn{2}{|c|}{$\mathrm{AB} \quad\left(\mathrm{m}^{2}\right)$} & \multicolumn{2}{|c|}{ VI } \\
\hline & & & A & $\mathrm{P}$ & A & $\mathrm{P}$ & A & $\mathrm{P}$ & A & $\mathrm{P}$ \\
\hline \multicolumn{11}{|l|}{ LAURACEAE } \\
\hline Nectandra grandiflora Nees & 18096 & 8,0 & 2 & 0 & 1 & 0 & 0,0154 & 0 & 1,18 & 0 \\
\hline \multicolumn{11}{|l|}{ LECYTHIDACEAE } \\
\hline $\begin{array}{l}\text { Cariniana domestica (Mart.) Miers. } \\
\text { MALVACEAE }\end{array}$ & 12456 & 25,0 & 0 & 1 & 0 & 1 & 0 & 0,2903 & 0 & 5,11 \\
\hline Guazuma ulmifolia Lam. & 12293 & 8,0 & 5 & 0 & 3 & 0 & 0,0142 & 0 & 3,16 & 0 \\
\hline Luehea divaricata Mart. \& Zucc. & & 14,0 & 2 & 0 & 1 & 0 & 0,0414 & 0 & 1,32 & 0 \\
\hline $\begin{array}{l}\text { Pseudobombax grandiflorum (Cav.) } \\
\text { A. Robyns }\end{array}$ & 18098 & 15,0 & 0 & 1 & 0 & 1 & 0 & 0,1408 & 0 & 2,89 \\
\hline \multicolumn{11}{|l|}{ MELIACEAE } \\
\hline Trichilia catigua A.Juss. & 18099 & 11,0 & 18 & 11 & 9 & 4 & 0,0642 & 0,1353 & 10,17 & 5,23 \\
\hline T. clausseni C.DC. & 18100 & 18,0 & 89 & 0 & 8 & 0 & 0,6810 & 0 & 26,40 & 0 \\
\hline T. pallens C.DC. & 18101 & 11,0 & 15 & 0 & 6 & 0 & 0,1103 & 0 & 7,72 & 0 \\
\hline \multicolumn{11}{|l|}{ MORACEAE } \\
\hline Ficus glabra Vell. & 18102 & 10,0 & 0 & 1 & 0 & 1 & 0 & 0,0040 & 0 & 0,87 \\
\hline \multicolumn{11}{|c|}{ MYRTACEAE } \\
\hline $\begin{array}{l}\text { Campomanesia guazumifolia (Cambess.) } \\
\text { O. Berg }\end{array}$ & 18103 & 7,0 & 1 & & 1 & & 0,0042 & & 0,92 & \\
\hline C. xanthocarpa O. Berg. & 18104 & 6,0 & 0 & 2 & 0 & 1 & 0 & 0,0100 & 0 & 0,95 \\
\hline Eugenia florida DC. & 18105 & 7,0 & 1 & 0 & 1 & 0 & 0,0028 & 0 & 0,92 & 0 \\
\hline \multicolumn{11}{|l|}{ NYCTAGINACEAE } \\
\hline Pisonia ambigua Heimerl & 18106 & 15,0 & 2 & 1 & 2 & 1 & 0,0763 & 0,0401 & 2,22 & 1,40 \\
\hline \multicolumn{11}{|l|}{ OCHNACEAE } \\
\hline Ouratea castaneifolia (DC.) Engl. & 18107 & & Flora & & & & & & & \\
\hline \multicolumn{11}{|l|}{ PIPERACEAE } \\
\hline Piper amalago L. & 18108 & 4,5 & 1 & 0 & 1 & 0 & 0,0024 & 0 & 0,91 & 0 \\
\hline \multicolumn{11}{|l|}{ RUBIACEAE } \\
\hline Alibertia concolor (Cham.) K. Schum. & 18109 & 6,0 & 3 & 2 & 2 & 1 & 0,0125 & 0,0069 & 2,06 & 0,91 \\
\hline Chomelia sericea Mül. Arg. & 18110 & 5,0 & 0 & 5 & 0 & 1 & 0 & 0,0176 & 0 & 1,07 \\
\hline Coutarea hexandra (Jacquin) K. Schum. & 18111 & 5,5 & 0 & 1 & 0 & 1 & 0 & 0,0026 & 0 & 0,84 \\
\hline Genipa americana $\mathrm{L}$. & 14582 & 16,0 & 3 & 0 & 2 & 0 & 0,0532 & 0 & 2,28 & 0 \\
\hline Guettarda sericea Mül. Arg. & 18112 & 7,0 & 2 & 0 & 1 & 0 & 0,0062 & 0 & 1,12 & 0 \\
\hline G. uruguensis Cham. \& Schltdl. & 18113 & 8,0 & 2 & 0 & 1 & 0 & 0,0098 & 0 & 1,14 & 0 \\
\hline \multicolumn{11}{|l|}{ RUTACEAE } \\
\hline Galipea jasminiflora (A.St.-Hil.) Engler & 18114 & 5,0 & 0 & 2 & 0 & 2 & 0 & 0,0075 & 0 & 1,72 \\
\hline \multicolumn{11}{|l|}{ SALICACEAE } \\
\hline Casearia gossypiosperma Briquet & 18095 & 15,0 & 4 & 17 & 3 & 8 & 0,0266 & 0,0884 & 3,04 & 7,76 \\
\hline Prockia crucis P.Bowne ex L. & 18117 & 8,0 & 2 & 0 & 1 & 0 & 0,0060 & 0 & 1,12 & 0 \\
\hline \multicolumn{11}{|l|}{ SAPINDACEAE } \\
\hline Allophylus sericeus Radlk. & 18115 & 12,0 & 47 & 3 & 7 & 3 & 0,2679 & 0,0204 & 15,40 & 2,72 \\
\hline Dilodendron bipinnatum Radlk. & 18116 & 16,0 & 6 & 9 & 1 & 1 & 0,1130 & 0,2400 & 2,48 & 4,36 \\
\hline SAPOTACEAE & & & & & & & & & & \\
\hline Pouteria torta (Mart.) Radlk. & 18118 & 16,0 & 1 & 0 & 1 & 0 & 0,0554 & 0 & 1,21 & 0 \\
\hline VERBENACEAE & & & & & & & & & & \\
\hline Aloysia virgata (Ruiz \& Pavón) A. Juss. & 18119 & 6,5 & 6 & 6 & 2 & 3 & 0,0377 & 0,0381 & 2,77 & 2,98 \\
\hline
\end{tabular}

clausseni (11\%), Holocalyx balansae (6,9\%), Allophylus sericeus (6,2\%), Trichilia catigua $(3,6 \%)$, Piptadenia gonoacantha (3,5\%), Casearia gossypiosperma e Sweetia fruticosa (2,6\%) e Machaerium brasiliense (2,5\%). Em Alpinópolis as dez espécies com maior densidade foram M. urundeuva (24\%), T. clausseni (17\%),
A. colubrina $(12,4 \%)$, A. sericeus $(9 \%), H$. balansae $(4,4 \%), T$. catigua e P. gonoacantha $(3,4 \%)$, Machaerium brasiliense (3,3\%), Trichilia pallens $(2,9 \%)$ e $L$. cultratus $(1,5 \%)$, totalizando $82 \%$ do número total de indivíduos. Em Passos, totalizando $76 \%$, encontraram-se A. colubrina (22\%), M. urundeuva $(13,6 \%), \quad H$. balansae $(11,5 \%)$, Casearia 
gossypiosperma (5,9\%), Aspidosperma discolor e Sweetia fruticosa (4,9\%), T. catigua $(3,8 \%)$, P. gonoacantha (3,5\%), Dilodendron bipinnatum (3,1\%) e Aspidosperma subincanum (2,8\%). Os três maiores valores de área basal $(82,2 \%$ do total) foram registrados para as espécies $A$. colubrina (42\%) M. urundeuva (38\%), e T. clausseni $(2,2 \%)$. Os maiores valores de VI encontrados variaram entre $68,08 \%$ e $10,85 \%$ e pertencem à apenas cinco espécies. A espécie de maior VI, A. colubrina, apresentou altos valores de densidade e área basal, enquanto $M$. urundeuva apresentou o segundo maior valor de área basal, o que contribuiu para ser a segunda em VI. Na estratificação da comunidade observa-se que quatro espécies atingem altura igual ou superior a $20 \mathrm{~m}, 34$ atingem de 10 a $18 \mathrm{~m}$ de altura e 23 são menores que $9 \mathrm{~m}$. O índice de diversidade de Shannon $\left(H^{\prime}\right)$ e o índice de equabilidade de Pielou $\left(J^{\prime}\right)$, foram de 2,97 nats ind. ${ }^{-1}$ e 0,72 , respectivamente. A distribuição de indivíduos por classes de diâmetro apresentou decréscimo do número de indivíduos no sentido das menores para as maiores classes diamétricas, embora tal decréscimo não tenha apresentado o formato clássico de $\mathrm{J}$ invertido devido ao número proporcionalmente elevado de indivíduos nas classes intermediárias (Fig. 2). Os indivíduos de Anadenanthera colubrina apresentaram maior número de indivíduos na primeira, terceira e quarta classes de diâmetro, enquanto os de Myracrodruon urundeuva apresentaram uma distribuição diamétrica com um grande número de indivíduos na classe de diâmetro central e números decrescentes em direção à primeira e última classe.

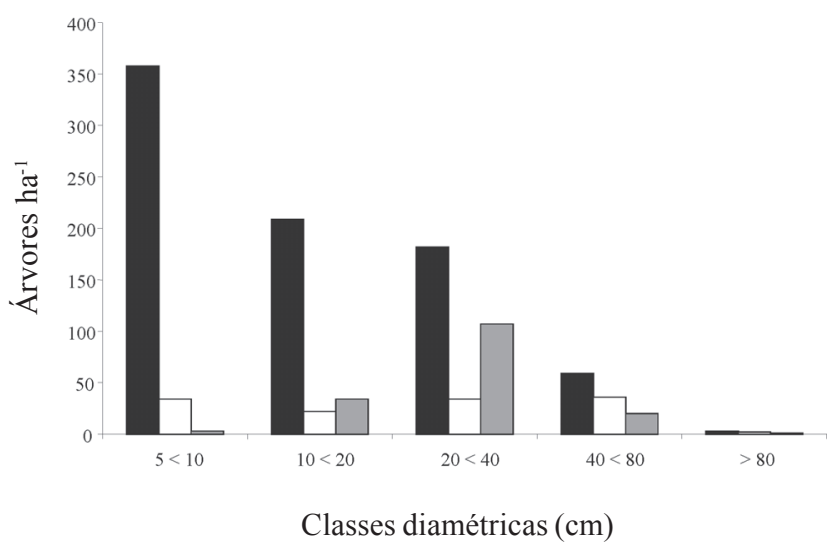

Figura 2. Distribuição da densidade por hectare de árvores com DAP maior ou igual a $5 \mathrm{~cm}$ em classes de diâmetro dos indivíduos da comunidade ( $\square$ ), de Anadenanthera colubrina $(\square)$ e de Myracrodruon urundeuva ( $\square$ ), nas parcelas utilizadas para amostrar as florestas de Alpinópolis e Passos (MG).
Distribuição das espécies - Os autovalores da CCA para os três primeiros eixos foram 0,339 (eixo 1), 0,201 (eixo 2) e 0,174 (eixo 3). Os autovalores dos três eixos foram baixos ( $<0,5$ sensu ter Braak 1995), indicando a existência de um gradiente curto, ou seja, com poucas substituições de espécies e predominância da variação nas abundâncias das espécies. Os três primeiros eixos explicaram apenas $24,2 \%$ da variância global, sendo $11,5 \%$ para o eixo $1,6,8 \%$ para o eixo 2 e $5,9 \%$ para o eixo 3, indicando muito 'ruído', ou variância remanescente não explicada pelas variáveis ambientais empregadas. No entanto 'ruído' elevado constitui uma característica comum em dados de vegetação e isto não prejudica a significância das relações espécieambiente (ter Braak 1987). De fato, as correlações espécie-ambiente foram altas, 0,921 (eixo 1), 0,876 (eixo2) e 0,895 (eixo 3), e o teste de permutação de Monte Carlo indicou que as abundâncias das espécies e as variáveis ambientais foram significativamente correlacionadas nos três eixos $(\mathrm{P}<0,01)$. As variáveis ambientais mais fortemente correlacionadas com o primeiro eixo foram drenagem e desnível e, com o segundo eixo, drenagem (Tab. 3). A soma de bases apresentou correlações relativamente baixas com ambos os eixos. As correlações entre as variáveis ambientais foram baixas. A ordenação das parcelas (Fig. 3A) permitiu fazer a separação das três classes de solos encontradas. As parcelas sobre Neossolos Litólicos (único tipo de solo encontrado no fragmento de Passos) formaram um grupo caracterizado por maior desnível (apenas $\mathrm{E}_{2}$ distanciou-se das demais por ser uma das menos acidentadas no fragmento) e pior drenagem. As parcelas sobre Latossolos Vermelhos formaram um grupo caracterizado por melhor drenagem, menor desnível e valores mais baixos da soma de bases. As parcelas sobre Nitossolos Háplicos agruparam-se por apresentar valores de desnível próximos àqueles dos Latossolos e também baixos valores de drenagem. O ordenação das espécies pela CCA (Fig 3B) sugeriu que as espécies Dilodendron bipinnatum, Tabebuia roseo-alba, Luehea divaricata, Peltophorum dubium, Trichilia catigua, Chloroleucon tortum, Bauhinia longifolia, Holocalyx balansae, Maytenus robusta e Genipa americana não apresentaram correlação com as variáveis ambientais. As seguintes espécies se correlacionaram com solos de melhor drenagem dos fragmentos (em ordem decrescente): Guettarda uruguensis, Nectandra grandiflora, Pera glabrata, Inga striata, Alibertia concolor, Copaifera langsdorffii, Trichilia pallens, Rollinia sylvatica, 
Tabela 3. Análise de correspondência canônica (CCA): correlações internas ('intraset') nos dois primeiros eixos de ordenação e matriz de correlações ponderadas para as variáveis ambientais utilizadas na análise. Correlações com valores absolutos $>0,5$ estão indicadas em negrito.

\begin{tabular}{|c|c|c|c|c|}
\hline \multirow[t]{2}{*}{ Variáveis ambientais } & \multicolumn{2}{|c|}{ Correlações ponderadas } & \multirow[t]{2}{*}{ Drenagem } & \multirow{2}{*}{$\begin{array}{c}\text { Soma de bases } \\
\text { S }\end{array}$} \\
\hline & Eixo 1 & Eixo 2 & & \\
\hline Drenagem & 0,776 & $0,548-$ & - & \\
\hline Soma de bases $-\mathrm{S}$ & $-0,173$ & $-0,151$ & $-0,222$ & - \\
\hline Desnível & $-0,830$ & 0,478 & $-0,365$ & 0,170 \\
\hline
\end{tabular}

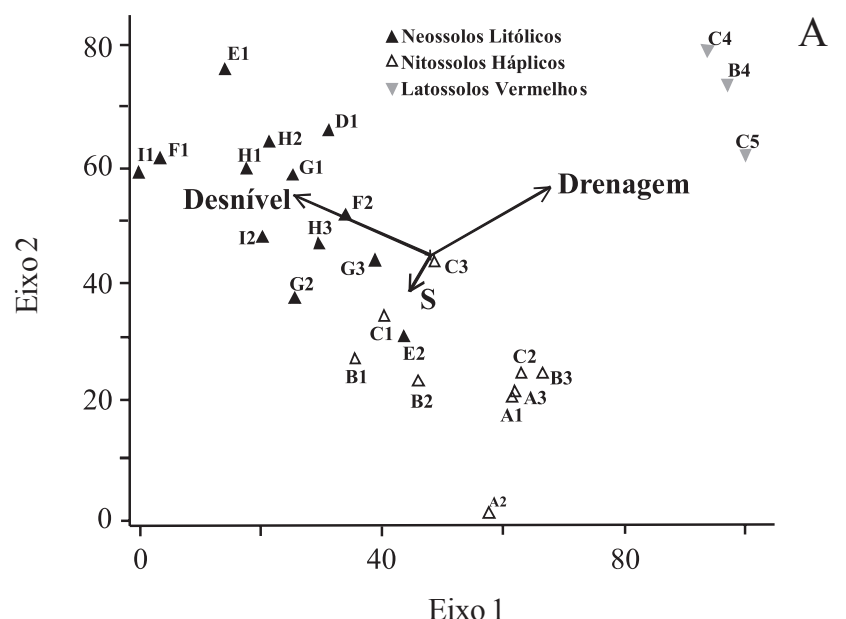

Eixo 1

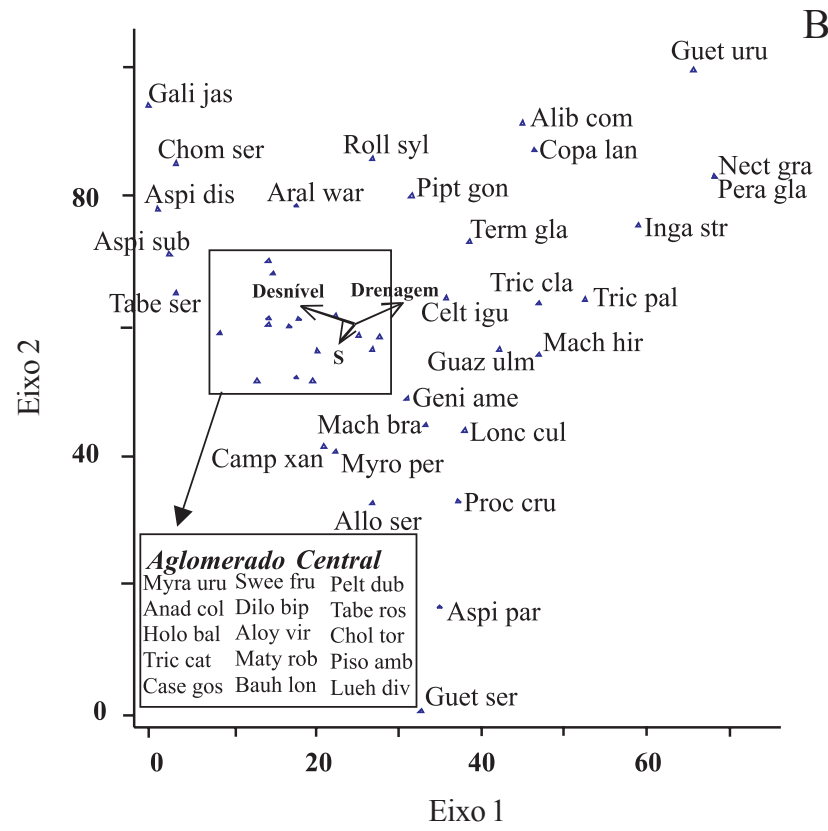

Figura 3. Análise de correspondência canônica: diagrama de ordenação das parcelas (A) e espécies (B) baseada na distribuição do número de indivíduos de 44 espécies em 25 parcelas utilizadas para amostrar as florestas de Alpinópolis e Passos, MG, e sua correlação com as cinco variáveis ambientais utilizadas (retas). As parcelas são identificadas conforme as Fig. 1A e 1B e classificadas nas três classes de solos. As espécies são indicadas pelo seu nome abreviado (os nomes completos estão na tab. 2).
Machaerium hirtum, Guazuma ulmifolia, Trichilia clausseni, Celtis iguanaea, Terminalia glabrescens, Piptadenia gonoacantha e Lonchocarpus cultratus. Algumas espécies se correlacionaram com maiores valores da soma de bases: Guettarda sericea, Aspidosperma parvifolium, Allophylus sericeus, Myroxylon peruiferum, Campomanesia xanthocarpa. Já as espécies Galipea jasminiflora, Chomelia sericea, Aspidosperma discolor, Aspidosperma subincanum, Aralia warmingiana e Tabebuia serratifolia estão presentes somente no fragmento de Passos onde há um acentuado desnível entre e dentro das parcelas. Entretanto, como os gradientes são curtos, a maioria das espécies se distribui por todo o gradiente, com algumas delas variando apenas em termos de abundância relativa.

\section{Discussão}

Perfil e contexto florístico - As famílias com maior riqueza de espécies no presente estudo, Fabaceae, Rubiaceae, Bignoniaceae, Anacardiaceae, Apocynaceae, Malvaceae, Meliaceae e Myrtaceae, também ocorrem nas florestas estacionais do estado de São Paulo (Leitão Filho 1987) e nas florestas ciliares já levantadas no estado de Minas Gerais (Gavilanes et al. 1992; Carvalho et al. 1995b; 1999; 2000a; 2000b; 2005a; 2005b; Vilela et al. 1995, entre outros), apenas com variações no posicionamento das famílias mais ricas. Gentry (1995b) indica a importância de Euphorbiaceae em florestas decíduas neotropicais; entretanto, no presente estudo a família foi representada por uma única espécie, Pera glabrata. Os estudos de Killen et al. (1998), em uma floresta tropical decidual localizada na Bolívia, demonstraram que o dossel das florestas deciduais maduras é dominado por árvores de Fabaceae, que árvores das famílias Bignoniaceae, Anacardiaceae e Bombacaceae são também abundantes, e no subdossel predominam 
árvores das famílias Sapindaceae e Myrtaceae. Aqui se obteve resultados semelhantes, considerando-se que Malvaceae engloba Bombacaceae. Das 28 famílias encontradas, 17 apresentaram apenas uma espécie, enquanto que Rodrigues \& Araújo (1997), Rodal et al. (1999), Carvalho et al. (1999), Pereira et al. (2002) e Silva \& Scariot (2003) encontraram aproximadamente metade do número de famílias representadas por uma espécie. Os gêneros mais ricos em espécies, nas florestas estudadas, Tabebuia, Trichilia, Aspidosperma, Campomanesia, Guettarda e Machaerium, também foram representados em outros levantamentos realizados em formações deciduais, nos trabalhos de Ratter et al. (1978), Rodrigues \& Araújo (1997), Rodal et al. (1999), Carvalho et al. (1999), Ivanaukas \& Rodrigues (2000), Pereira et al. (2002) e Silva \& Scariot (2003), além de outros que aí ocorreram como Anadenanthera, Astronium, Cariniana, Dilodendron, Myracrodruon e Piptadenia. Entretanto, as florestas deciduais estudadas apresentam baixa similaridade florística com as semideciduais, com apenas algumas espécies em comum. Essa diferença está basicamente ligada aos diferentes tipos de solos que nas matas mesófilas decíduas ocorrem, geralmente, em solos mesotróficos relativamente férteis e eutróficos e as semideciduais, em solos distróficos muito pobres em nutrientes (Ratter et al. 1973; 1978).

Diversidade, estrutura e distribuição das espécies - O número de espécies encontrado (65), pode ser considerado pequeno se comparado aos estudos realizados em florestas ripárias semideciduais nas Bacias dos rios Grande, Doce e São Francisco, em Minas Gerais: Madre Deus de Minas, 192 espécies (Oliveira Filho et al. 1994b); Bom Sucesso, 245 espécies (Carvalho et al. 1995a); Itutinga, 253 espécies (Vilela et al. 1995); Luminárias, 201 espécies (Rodrigues et al. 2003); Coqueiral, 243 espécies (Rocha et al. 2005); Itambé do Mato Dentro, 216 espécies (Carvalho et al. 2000a); Parque Estadual do Rio Doce, 143 espécies (Lopes et al. 2002); Martinho Campos, 121 espécies (Carvalho et al. 2000b) e Três Marias, 117 espécies (Carvalho et al. 2005b). Entretanto, o número de espécies é semelhante ao encontrado por Carvalho et al. (1999) numa floresta ripária decidual do baixo Paranaíba, em Santa Vitória, MG, (60 espécies) e superior àquele encontrado por Silva \& Scariot (2003) em uma floresta estacional decidual em afloramento calcário (36 espécies), na fazenda São José, em São Domingos, GO, área pertencente à bacia do rio Paranã. Já o levantamento realizado por Ivanauskas \& Rodrigues (2000) numa floresta estacional decidual em Piracicaba, SP, registrou um total de 110 espécies, valor que ultrapassa a amplitude do número de espécies, para florestas deciduais, segundo Gentry (1988). Os índices de Shannon $\left(H^{\prime}=2,97\right.$ nats. ind. $\left.{ }^{-1}\right)$ e de equabilidade de Pielou $\left(\mathrm{J}^{\prime}=0,72\right)$ encontrados, foram semelhantes àqueles obtidos em florestas estacionais deciduais estudadas no Brasil: Santa Vitória, MG $\left(\mathrm{H}^{\prime}=2,88\right.$ nats. ind. ${ }^{-1}$ e $\left.\mathrm{J}^{\prime}=0,70\right)$ (Carvalho et al. 1999); Triângulo Mineiro ( $\mathrm{H}^{\prime}=3,72$ nts. ind. ${ }^{-1} \mathrm{e}$ $\mathrm{J}^{\prime}=0,79$ ) (Werneck et al. 2000); São Domingos, GO $\left(\mathrm{H}^{\prime}=2,99\right.$ nats. ind. ${ }^{-1}$ e J' $=0,83$ ) (Silva \& Scariot (2003); Agreste Paraibano (H' $=2,99$ nts. ind. ${ }^{-1} \mathrm{e}$ $\mathrm{J} "=0,76)$ (Pereira et al. 2002); e em Piracicaba, SP $\left(\mathrm{H}^{\prime}=3,00\right.$ nats. ind.$^{-1}$ e $\left.\mathrm{J}^{\prime}=0,70\right)$ (Ivanauskas \& Rodrigues 2000). Entretanto, valores maiores de índices, principalmente os de diversidade, são encontrados nas florestas semideciduais, fato este já esperado, pois segundo Gentry (1988; 1995a), as florestas deciduais são menos diversas, apresentando, algumas vezes, menos da metade das espécies arbóreas encontradas em outras florestas tropicais. O declínio em diversidade com o aumento da interiorização e do caráter decíduo das florestas no domínio Atlântico é fato bem conhecido (Oliveira Filho \& Fontes 2000). O valor de $J^{\prime}(0,72)$ encontrado indica uma distribuição desigual dos indivíduos amostrados entre as espécies presentes, sendo que algumas poucas espécies respondem por uma grande parcela dos indivíduos levantados. O predomínio em número ou massa de poucas espécies em uma comunidade, também conhecido como dominância ecológica, não é incomum em florestas tropicais (Richards 1952), particularmente entre as florestas estacionais do Brasil Central (Oliveira Filho \& Ratter 2000).

A densidade de árvores encontrada no presente estudo, de 811 árvores ha ${ }^{-1}$, situa-se em posição intermediária entre os levantamentos realizados em florestas deciduais, utilizando o mesmo diâmetro mínimo e que variam de 536 árvores ha-1, em São Domingos, GO (Silva \& Scariot 2003), a 2.176 árvores ha ${ }^{-1}$, em Piracicaba, SP (Ivanauskas \& Rodrigues 2000). Quanto à área basal, que foi de $18,06 \mathrm{~m}^{2} \mathrm{ha}^{-1}$, as florestas de Alpinópolis e Passos, MG, também situam-se em posição intermediária, comparada às florestas de São Domingos, GO $\left(8,45 \mathrm{~m}^{2} \mathrm{ha}^{-1}\right)$ (Silva \& Scariot 2003) e Piracicaba, SP $\left(29,7 \mathrm{~m}^{2} \mathrm{ha}^{-1}\right)$ (Ivanauskas \& Rodrigues 2000). Nas florestas 
semideciduais, valores de densidade variam de 1.493 árvores ha ${ }^{-1}$, em Coqueiral, MG (Rocha et al. 2005) a 1.830 árvores $\mathrm{ha}^{-1}$ em Luminárias, MG (Rodrigues et al. 2003)) e de área basal de 29,31 árvores $\mathrm{m}^{2} \mathrm{ha}^{-1}$ em Luminárias, $\mathrm{MG}$ (Rodrigues et al. 2003) a $36,38 \mathrm{~m}^{2} \mathrm{ha}^{-1} \mathrm{em}$ Coqueiral, MG (Rocha et al. 2005).

Anadenanthera colubrina, popularmente conhecida por angico-branco e Myracrodruon urundeuva, popularmente conhecida por aroeira-dosertão, são de forma significativa, as espécies mais importantes nas florestas de Alpinópolis e Passos. Essas espécies ocorrem com muita freqüência em outros levantamentos em florestas deciduais, inclusive, como fortes indicadoras de manchas de solos mais férteis no Brasil Central (Prado \& Gibbs 1993). A dominância destas duas espécies em florestas deciduais é muito maior que a encontrada em florestas semideciduais, ou seja, provavelmente há um alto grau de exclusão competitiva. De fato, nas áreas de florestas ciliares de Minas Gerais, já mencionadas na introdução deste artigo, as duas espécies só foram registradas nas formações deciduais de Conquista (Carvalho et al. 1996), Santa Vitória (Carvalho et al. 1999) e Três Marias (Carvalho et al. 2005b), ocorrendo de forma abundante e com alturas ao redor de $20 \mathrm{~m}$. A. colubrina ocorre desde o Nordeste até o Estado do Paraná e $M$. urundeuva está restrita às regiões Nordeste e Centro-Oeste do Brasil (Lorenzi 1998). Entre as espécies mais abundantes, apenas Trichilia clausseni apresentou uma baixa freqüência, indicando uma distribuição agrupada de indivíduos, ocorrendo em parcelas próximas, o que facilita o processo de dispersão e estabelecimento de plantas. Segundo Lorenzi (1998), essa espécie se adapta bem em solos pedregosos do topo de morros, onde pode chegar a representar a espécie dominante.

$\mathrm{Na}$ estratificação da comunidade, $A$. colubrina e M. urundeuva contribuíram com a maior parte dos indivíduos da comunidade nas classes de diâmetro de 20 a $40 \mathrm{~cm}$ e 40 a $80 \mathrm{~cm}$. A concentração dos indivíduos destas duas espécies dominantes nestas classes de tamanho, fugindo da distribuição J invertido, é o principal fator responsável pela comunidade também não seguir esta distribuição.

A clara separação das parcelas de acordo com os tipos de solo e as variáveis ambientais a eles associados, tais como drenagem, declividade e status nutricional, indicam que tais fatores afetam a distribuição das espécies nas áreas, não tanto em termos de substituição de espécies, mas principalmente em termos de variações nas suas abundâncias relativas. Carvalho et al. (2005b), trabalhando em um trecho de floresta ripária que inclui floresta decidual, às margens do Rio São Francisco, encontraram resultados claramente concordantes com os do presente trabalho, ou seja, uma forte correlação entre a distribuição das espécies na área e os diferentes tipos de solo, sendo isto vinculado a diferenças de drenagem, fertilidade e declividade. Também Oliveira Filho et al. (1998) mostraram que a distribuição de espécies em uma floresta decidual da bacia do Rio Paranaíba, Minas Gerais, estava fortemente associada à drenagem da água do solo e esta associada a declividade. A topografia da área e sua associação à drenagem e, secundariamente, as variações de fertilidade estão entre os principais fatores ligados à variação da distribuição de espécies em florestas deciduais (Oliveira Filho et al. 1990).

A despeito do presente trabalho haver detectado uma clara correlação entre a distribuição de espécies e as características do substrato, com ênfase para desnível e drenagem, foi também identificado um razoável montante de variância não explicada pelas variáveis ambientais fornecidas (o 'ruído'). O histórico de perturbação diferenciada é uma possível variável não considerada e de difícil controle. Se perturbações naturais promovidas pelo processo de silvigênese podem criar um mosaico de eco-unidades de variada composição e estrutura (Oldeman 1983), aquelas promovidas pelo homem e pelo gado constituem um fator adicional a ser considerado na área de estudos (Toniato \& Oliveira Filho 2004). Acrescente-se a isto que ainda se pode deixar uma larga margem para efeitos estocásticos na distribuição das espécies. Desta forma, é necessário ter em mente que correlações detectadas entre a distribuição de espécies e variáveis do substrato, ainda que verdadeiras, sempre refletem um pequeno fragmento da realidade.

\section{Agradecimentos}

Este trabalho faz parte do 'Estudo integrado da vegetação ciliar no entorno de nascentes, rios e reservatórios' e contou com o apoio do $\mathrm{CNPq} / \mathrm{CT}$ HIDRO. Agradecemos aos proprietários das áreas, Sr. Ranulfo e Usina de Açúcar Minasul; ao Prof. Ary Teixeira de Oliveira Filho; aos acadêmicos da UFLA, Ana Cecília Gonçalves, Daniel Leão Bandeira de Melo, Gentil Antônio de Souza Júnior, Gleyce Campos Dutra e Simone Soraya Brito Costa. 


\section{Referências bibliográficas}

APG II. 2003. An update of the Angiosperm Phylogeny Group classification for the orders and families of flowering plants: APG II. Botanical Journal of the Linnaean Society 141: 399-436.

Barbosa, L.M. 1989. Estudos interdisciplinares do Instituto de Botânica em Moji Guaçu, SP. Pp. 171-191. In: L.M. Barbosa (eds). Anais do Simpósio Sobre Mata Ciliar. Campinas, Fundação Cargill.

Black, G.A.; Dobzhansky, T.H. \& Pavan, C. 1950. Some attempts to estimate species diversity and population density of trees em Amazonian forests. Botanical Gazette 111: 413-425.

Botrel, R.T.; Oliveira Filho, A.T.; Rodrigues, L.A. \& Curi, N. 2002. Influência do solo e topografia sobre as variações da composição florística e estrutura da comunidade arbóreo-arbustiva de uma floresta estacional semidecidual em Ingaí, MG. Revista Brasileira de Botânica 25: 195-213.

BRASIL. 1992. Normais Climatológicas: 1961-1990. Ministério da Agricultura, Departamento Nacional de Meteorologia.

Brinson, M.M. 1990. Riverine forest. Pp. 87-141. In: A.E. Lugo; M.M. Brinson \& S. Brown (eds.). Ecosystems of World 15: Forested Wetlands. Amsterdan, Elsevier.

Brower, J.E. \& Zar, J.H. 1984. Field and laboratory methods for general ecology. W.M.C. Brow, Dubuque.

Carvalho, D.A.; Oliveira Filho, A.T.; Vilela, E.A. \& Gavilanes, M.L. 1995a. Estrutura fitossociológica de mata ripária do alto Rio Grande (Bom Sucesso, MG). Revista Brasileira de Botânica 18: 39-49.

Carvalho, D.A.; Oliveira Filho, A.T.; Vilela, E.A. \& Gavilanes, M.L. 1995b. Flora arbustivo-arbórea de uma floresta ripária no alto Rio Grande em Bom Sucesso, MG. Acta Botanica Brasilica 9: 231-245.

Carvalho, D.A.; Oliveira Filho, A.T. \& Vilela, E.A. 1996. Flora arbustivo-arbórea de mata ripária do médio Rio Grande (Conquista, MG). Cerne 2:48-68.

Carvalho, D.A.; Oliveira Filho \& Vilela, E.A. 1999. Florística e fitossociologia da vegetação arbórea-arbustiva de floresta ripária decídua do baixo Paranaíba (Santa Vitória, Minas Gerais). Revista Árvore 23: 311-320.

Carvalho, D.A.; Oliveira Filho, A.T. \& Vilela, E.A. 2000a. Composição florística e estrutura fitossociológica da vegetação arbóreo-arbustiva de uma floresta ripária do alto São Francisco (Martinho Campos, Minas Gerais). Boletim do Herbário Ezechias Paulo Heringer 6: 5-22.

Carvalho, D.A.; Oliveira Filho, A.T.; Vilela, E.A. \& Curi, N. 2000b. Florística e estrutura da vegetação arbórea de um fragmento de floresta semidecidual às margens do reservatório da usina Dona Rita (Itambé do Mato Dentro, MG). Acta Botanica Brasilica 14: 37-55.

Carvalho, D.A.; Oliveira Filho, A.T.; Van den Berg, E.; Fontes, M.A.L.; Vilela, E.A.; Melo-Marques, J.J.G.S. \& Carvalho,W. 2005a. Variações florísticas e estruturais do componente arbóreo de uma floresta ombrófila altomontana às margens do rio Grande, Bocaina de Minas, MG, Brasil. Acta Botanica Brasilica 19(1): 91-109.
Carvalho, D.A.; Oliveira Filho, A.T.; Vilela, E.A.; Curi, N.; Van den Berg, E.; Fontes, M.A. \& Botezelli, L. 2005b. Distribuição de espécies arbóreo-arbustivas ao longo de um gradiente de solos e topografia em um trecho de floresta ripária do Rio São Francisco em Três Marias, MG, Brasil. Revista Brasileira de Botânica 28(2): 329-345.

Durigan, G.; Rodrigues, R.R. \& Schiavini, I. 2000. A heterogeneidade ambiental definindo a metodologia de amostragem da floresta ciliar. Pp. 159-167. In: R.R. Rodrigues; H.F. Leitão Filho (eds.). Matas ciliares: conservação e recuperação. São Paulo, Edusp.

EMBRAPA. 1997. Manual de métodos de análises de solo. 2 ed. Empresa Brasileira de Pesquisa Agropecuária, Centro Nacional de Pesquisa de Solos, Rio de Janeiro.

EMBRAPA. 1999. Sistema brasileiro de classificação de solos. Rio de Janeiro, Empresa Brasileira de Pesquisa Agropecuária, Centro Nacional de Pesquisa de Solos.

Gavilanes, M.L.; Oliveira Filho, A.T.; Carvalho, D.A. \& Vilela, E.A. 1992. Flora arbustivo-arbórea de uma mata ciliar do alto Rio Grande em Madre de Deus de Minas, MG. Daphne 2: $15-24$

Gentry, A.H. 1988. Changes in plant community diversity and floristic composition on environmental and geographical gradients. Annals of the Missouri Botanical Garden 75: 1-34.

Gentry, A.H. 1995a. Patterns of diversity and floristic composition in neotropical montane forests. Pp.103-126. In: S.P. Churchill; H. Balslev; E. Forero \& J.L. Luteyn (eds.). Biodiversity and Conservation of Neotropical Montane Forests: Proceedings of Neotropical Montane Forest Biodiversity and Conservation Symposium. New York, The New York Botanical Garden.

Gentry, A.H. 1995b. Diversity and floristic composition of neotropical dry forests. Pp. 146-194. In: S.H. Bullocck; H.A. Mooney \& E. Medina. Seasonal Dry Tropical Forests. Cambridge, Cambridge University Press.

IGAM 1998. Bacias hidrográficas do estado de Minas Gerais. Belo Horizonte, Instituto Mineiro de Gestão das Águas.

Ivanauskas, N.M. \& Rodrigues, R.R. 2000. Florística e fitossociologia de remanescentes de floresta estacional decidual em Piracicaba, São Paulo, Brasil. Revista Brasileira de Botânica 23: 291-304.

Jacomine, P.K.T. 2000. Solos sob matas ciliares. Pp. 27-31. In: R.R. Rodrigues \& H.F. Leitão Filho (eds.). Matas ciliares: conservação e recuperação. São Paulo, Edusp.

Killen, T.; Jardim, A.; Manami, F.; Saraiva, P. \& Rojas, N. 1998. Diversity, composition, and structure of a tropical deciduous forest in the Ciquitania region of Santa Cruz, Bolívia. Journal of Tropical Ecology 14(6): 803-827.

Leitão Filho, H.F. 1987. Considerações sobe a florística de florestas tropicais e sub-tropicais do Brasil. IPEF 35: $41-46$

Lopes, W.P.; Silva, A.F.; Souza, A.L. \& Neto, J.A.A.M. 2002. Estrutura fitossociológica de um trecho de vegetação arbórea no Parque Estadual do Rio Doce-Minas Gerais, Brasil. Acta Botanica Brasilica 16(4): 443-456. 
Lorenzi, H. 1998. Árvores brasileiras: manual de identificação e cultivo de plantas arbóreas nativas do Brasil. v.1 Nova Odessa, Plantarum.

Martins, F.R. 1989. Fitossociologia de florestas do Brasil: um histórico bibliográfico. Pesquisa 40: 103-164.

McCune, B. \& Mefford, M.J. 1999. PC-ORD version 4.0., multivariate analysis of ecological data, Users guide. MjM Sftware Design, Glaneden Beach.

Mueller-Dombois, D. \& Ellenberg, H. 1974. Aims and methods of vegetation ecology. New York, J. Wiley.

Oldeman, R.A.A. 1983. Tropical rain forest: architecture, sylvigeneis and diversity. Pp. 139-150. In: S.L. Sutton; T.C. Whitmore \& A.C. Chadwick (eds.). Tropical rain forest: ecology and management. Oxford, Blackwell.

Oliveira Filho, A.T. \& Fontes, M.A.L. 2000. Patterns of Floristic Differentiation among Atlantic Forests in Southeastern Brazil and the Influence of Climate. Biotropica 32: 793-810.

Oliveira Filho, A.T. \& Ratter, J.A. 2000. Padrões florísticos das matas ciliares da região dos cerrados e a evolução das paisagens do Brasil Central durante o Quaternário tardio. Pp. 73-89. In: R.R. Rodrigues \& H.F. Leitão-Filho (eds.). Matas ciliares: conservação e recuperação. São Paulo, Edusp.

Oliveira Filho, A.T.; Ratter, J.A. \& Shepherd, G.J. 1990. Floristic composition and community structure of a central Brazilian gallery forest. Flora 184: 103-117.

Oliveira Filho, A.T.; Vilela, E.A.; Carvalho, D.A. \& Gavilanes, M.L. 1994a. Differentiation of streamside and upland vegetation in an area of montane semideciduous forest in southeastern Brazil. Flora 189: 1-19.

Oliveira Filho, A.T.; Vilela, E.A.; Gavilanes, M.L. \& Carvalho, D.A. 1994b. Comparison of the woody flora and soils of six areas of montane semideciduous forest in Southern Minas Gerais, Brazil. Edinburgh Journal of Botany 51: 335-389.

Oliveira Filho, A.T.; Vilela, E.A.; Carvalho, D.A. \& Gavilanes, M.L. 1994c. Effects of soils and topography on the distribution of tree species in a tropical riverine forest in south-eastern Brazil. Journal of Tropical Ecology 10: 483-508.

Oliveira Filho, A.T.; Vilela, E.A.; Gavilanes, M.L. \& Carvalho, D.A. 1994d. Effect of flooding regime and understorey bamboos on the physiognomy and tree species composition of a tropical semideciduous forest in Southeastern Brazil. Vegetatio 113: 99-124.

Oliveira Filho; A.T.; Curi, N.; Vilela, E.A. \& Carvalho, D.A. 1997. Tree species distribution along soil catenas in a riverside semideciduous forest in Southeastern Brazil. Flora 192: 47-64.

Oliveira Filho, A.T.; Curi, N.; Vilela, E.A. \& Carvalho, D.A. 1998. Effects of canopy gaps, topography, and soils on the distribution of woody species in a central Brazilian deciduous dry forest. Biotropica 30: 362-372.

Oliveira Filho, A.T.; Curi, N.; Vilela, E.A. \& Carvalho, D.A. 2001. Variation in tree community composition and structure with changes in soil properties within a fragment of semideciduous forest in south-eastern Brazil. Edinburgh Journal of Botany 58: 139-158.
Oliveira Filho, A.T.; Carvalho, D.A.; Vilela, E.A.; Curi, N. \& Fontes, M.A.L. 2004. Diversity and structure of the community of a fragment of tropical secondary forest of the Brazilian Atlantic forest domain 15 and 40 years after logging. Revista Brasileira de Botânica 27(4): 685-701.

Pereira, I.M.; Andrade, L.A.; Barbosa, M.R.V. \& Sampaio, E.V.S.B. 2002. Composição florística e análise fitossociológica do componente arbustivo-arbóreo de um remanescente florestal no Agreste Paraibano. Acta Botanica Brasilica 16: 357-369.

Pires, J.M. \& Koury, H.M. 1958. Estudo de um trecho de mata de várzea próximo de Belém. Boletim técnico I.A.N. 36: 3-44.

Prado, D.E. \& Gibbs, P.E. 1993. Patterns of species distribution in the dry seasonal forests of South América. Annals of the Missouri Botanical Garden 80: 902-927.

RADAMBRASIL 1983. Levantamento de Recursos Naturais. Rio de Janeiro, Ministério das Minas e Energia.

Ratter, J.A.; Askew, G.P.; Montgomery, R.F. \& Gifford, D.R. 1978. Observations on forests of some mesotrophic soils in central Brazil. Revista Brasileira de Botânica 1: 47-58

Ratter, J.A.; Richards,P.W.; Argent, G. \& Gifford, D.R. 1973. Observations on the vegetation of northeastern Mato Grosso 1 . The woody vegetation types of the XavantinaCachimbo Expedition area. Philosophical Transactions of the Royal Society of London, Série B-Biological 266: 449-492

Richards, P.W. 1952. The tropical rain forest. Cambridge, Cambridge University Press.

Rocha, C.T.V.; Carvalho, D.A.; Fontes, M.A.L.; OliveiraFilho, A.T.; Van de Berg, E. \& Melo-Marques, J.J.G.S. 2005. Comunidade arbórea de um continuum entre floresta paludosa e de encosta em Coqueiral, Minas Gerais. Revista Brasileira de Botânica 28(2): 203-217.

Rodal, M.J.N.; Nascimento, L.M. \& Melo, A.L. 1999. Composição florística de um trecho de vegetação arbustiva caducifólia, no município de Ibimirim, PE, Brasil. Acta Botanica Brasilica 13: 15-28.

Rodrigues, W.A. 1961. Estudo preliminar de mata de várzea alta de uma ilha do baixo Rio Negro de solo argiloso e úmido. Publicação 10. Manaus, Instituto Nacional de Pesquisa da Amazônia

Rodrigues, L.A. \& Araújo, G.M. 1997. Levantamento florístico de uma mata decídua em Uberlândia, Minas Gerais, Brasil. Acta Botanica Brasilica 11: 229-236.

Rodrigues, R.R. \& Nave, A.G. 2000. Heterogeneidade florística das matas cilaires. Pp. 45-71. In: R.R. Rodrigues \& H.F. Leitão Filho (eds.). Matas ciliares: conservação e recuperação. São Paulo, Edusp.

Rodrigues, L.A.; Carvalho, D.A.; Oliveira Filho, A.T.; Botrel, R.T. \& Silva, E.A. 2003. Florística e estrutura da comunidade arbórea de um fragmento florestal em Luminárias, MG. Acta Botanica Brasilica 17: 71-97.

Shepherd, G.J. 1994. FITOPAC 2.1: manual do usuário. Campinas, Universidade Estadual de Campinas. 
Silva, L.A.; Scariot, A. 2003. Composição florística e estrutura da comunidade arbórea em uma floresta estacional decidual em afloramento calcário (Fazenda São José, São Domingos, GO, Bacia do Rio Paraná). Acta Botanica Brasilica 17: 305-313.

Soares, A.C.P.; Dardenne, M.A.; Hasui, Y; Castro, F.D.C. \& Carvalho, M.V.A. 1994. Nota explicativa dos mapas geológico, metalogenético e de ocorrência minerais do Estado de Minas Gerais. Belo Horizonte, Comig.

ter Braak, C.J.F. 1987. The analysis of vegetationenvironment relationship by canonical correspondence analysis. Vegetatio 69: 69-77.

ter Braak, C.J.F. 1995. Ordination. Pp. 91-173. In: R.H.G. Jongman, C.J.F. ter Braak \& O.F.R. van Tongeren (eds.). Data analysis in community and landscape ecology. Cambrigde, Cambrigde University Press.

Toniato, M.T.Z. \& Oliveira Filho, A.T. 2004. Variations in tree community composition and structure in a fragment of tropical semideciduous forest in southeastern Brazil related to different human disturbance histories. Forest Ecology and Management 198: 319-339.

van den Berg, E. \& Oliveira Filho, A.T. 2000. Composição florística e estrutura fitossociológica de uma floresta ripária em Itutinga, MG, e comparação com outras áreas. Revista Brasileira de Botânica 23: 231-253.
Veloso, H.P.; Rangel Filho, A.L.R. \& Lima, J.C.A. 1991. Classificação da vegetação brasileira adaptada a um sistema universal. Rio de Janeiro, Instituto Brasileiro de Geografia e Estatística.

Vilela; E.A.; Oliveira Filho, A.T.; Gavilanes, M.L. \& Carvalho, D.A. 1993. Espécies de matas ciliares com potencial para estudos de revegetação no Alto Rio Grande, MG. Revista Árvore 17: 117-128.

Vilela, E.A.; Oliveira Filho, A.T.; Carvalho, D.A. \& Gavilanes, M.L. 1994. Fitossociologia e fisionomia de mata semidecídua margeando o reservatório de Camargos em Itutinga, Minas Gerais. Ciência e Prática 18: 408-414.

Vilela, E.A.; Oliveira Filho, A.T.; Carvalho, D.A. \& Gavilanes, M.L. 1995. Flora arbustivo-arbórea de um fragmento de mata ciliar no alto rio Grande, Itutinga, Minas Gerais. Acta Botanica Brasilica 9: 87-100.

Vilela, E.A.; Oliveira Filho, A.T. \& Carvalho, D.A. 1999. Fitossociologia de floresta ripária do médio rio Grande, Conquista, MG. Revista Árvore 23: 423-433.

Werneck, M.S.; Franceschinelli, E.V. \& Tameirão-Neto, E. 2000. Mudanças na florística e estrutura de uma floresta decídua durante um período de quatro anos (1994-1998), na região do Triângulo Mineiro, MG. Revista Brasileira de Botânica 23: 399-411. 